NASA/CR-2000-210355

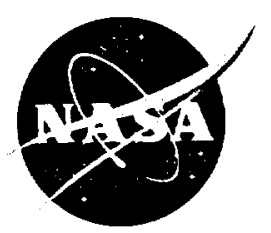

\section{Theta-Pinch Thruster for Piloted Deep Space Exploration}

Mike R. LaPointe

Ohio Aerospace Institute, Brook Park, Ohio
AIAA 2000-3365

$4 \% 9073$ 
Since its founding, NASA has been dedicated to the advancement of aeronautics and space science. The NASA Scientific and Technical Information (STI) Program Office plays a key part in helping NASA maintain this important role.

The NASA STI Program Office is operated by Langley Research Center, the Lead Center for NASA's scientific and technical information. The NASA STI Program Office provides access to the NASA STI Database, the largest collection of aeronautical and space science STI in the world. The Program Office is also NASA's institutional mechanism for disseminating the results of its research and development activities. These results are published by NASA in the NASA STI Report Series, which includes the following report types:

- TECHNICAL PUBLICATION. Reports of completed research or a major significant phase of research that present the results of NASA programs and include extensive data or theoretical analysis. Includes compilations of significant scientific and technical data and information deemed to be of continuing reference value. NASA's counterpart of peerreviewed formal professional papers but has less stringent limitations on manuscript length and extent of graphic presentations.

- TECHNICAL MEMORANDUM. Scientific and technical findings that are preliminary or of specialized interest, e.g., quick release reports, working papers, and bibliographies that contain minimal annotation. Does not contain extensive analysis.

- CONTRACTOR REPORT. Scientific and technical findings by NASA-sponsored contractors and grantees.
- CONFERENCE PUBLICATION. Collected papers from scientific and technical conferences, symposia, seminars, or other meetings sponsored or cosponsored by NASA.

- SPECIAL PUBLICATION. Scientific, technical, or historical information from NASA programs, projects, and missions, often concerned with subjects having substantial public interest.

- TECHNICAL TRANSLATION. Englishlanguage translations of foreign scientific and technical material pertinent to NASA's mission.

Specialized services that complement the STI Program Office's diverse offerings include creating custom thesauri, building customized data bases, organizing and publishing research results ... even providing videos.

For more information about the NASA STI Program Office, see the following:

- Access the NASA STI Program Home Page at $h t t p: / / w w w . s t i . n a s a . g o v$

- E-mail your question via the Internet to help@sti.nasa.gov

- Fax your question to the NASA Access Help Desk at (301) 621-0134

- Telephone the NASA Access Help Desk at (301) 621-0390

- Write to:

NASA Access Help Desk NASA Center for AeroSpace Information 7121 Standard Drive Hanover, MD 21076 


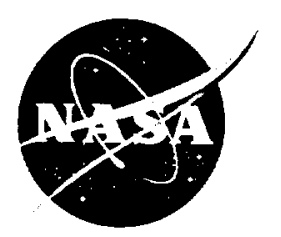

\section{Theta-Pinch Thruster for Piloted Deep Space Exploration}

Mike R. LaPointe

Ohio Aerospace Institute, Brook Park, Ohio

Prepared for the

36th Joint Propulsion Conference and Exhibit cosponsored by AIAA, ASME, SAE, and ASEE Huntsville, Alabama, July 17-19, 2000

Prepared under Grant NAG3-2230

National Aeronautics and Space Administration

Glenn Research Center 


\section{Acknowledgments}

This research was performed by the author for the Horizon Technologies Development Group, Cleveland, Ohio, under a Phase I grant from the NASA Institute for Advanced Concepts, Grant No. 07600-022.

This report contains preliminary

findings, subject to revision as analysis proceeds.

Available from

NASA Center for Aerospace Information

7121 Standard Drive

Hanover, MD 21076

Price Code: A03
National Technical Information Service 5285 Port Royal Road Springfield, VA 22100 Price Code: A03

Available electronically at http://gltrs.grc.nasa.gov/GLTRS 


\title{
THETA-PINCH THRUSTER FOR PILOTED DEEP SPACE EXPLORATION
}

\author{
Michael R. LaPointe \\ Ohio Aerospace Institute \\ Brook Park, Ohio 44142
}

\begin{abstract}
A new high-power propulsion concept that combines a rapidly pulsed theta-pinch discharge with upstream particle reflection by a magnetic mirror was evaluated under a Phase I grant awarded through the NASA Institute for Advanced Concepts. Analytic and numerical models were developed to predict the performance of a theta-pinch thruster operated over a wide range of initial gas pressures and discharge periods. The models indicate that a $1-\mathrm{m}$ radius, $10-\mathrm{m}$ long thruster operated with hydrogen propellant could provide impulse-bits ranging from $1 \mathrm{~N}-\mathrm{s}$ to $330 \mathrm{~N}-\mathrm{s}$ with specific impulse values of $7,500 \mathrm{~s}$ to $2,500 \mathrm{~s}$, respectively. A pulsed magnetic field strength of 2-T is required to compress and heat the preionized hydrogen over a $10^{-3} \mathrm{~s}$ discharge period, with about $60 \%$ of the heated plasma exiting the chamber each period to produce thrust. The unoptimized thruster efficiency is low, peaking at approximately $16 \%$ for an initial hydrogen chamber pressure of 100 -Torr. The specific impulse and impulse-bit at this operating condition are $3,500 \mathrm{~s}$ and $90 \mathrm{~N}-\mathrm{s}$, respectively, and the required discharge energy is approximately $9 \times 10^{6} \mathrm{~J}$. For a pulse repetition rate of $10-\mathrm{Hz}$, the engine would produce an average thrust of $900 \mathrm{~N}$ at $3,500 \mathrm{~s}$ specific impulse. Combined with the electrodeless nature of the device, these performance parameters indicate that theta-pinch thrusters could provide unique, long-life propulsion systems for piloted deep space mission applications.
\end{abstract}

\section{INTRODUCTION}

Characteristic mission velocities required for the piloted deep space exploration scenarios envisioned by the NASA Human Exploration and Development of Space Strategic Enterprise typically fall in the range of $10^{4}$ to $10^{5} \mathrm{~m} / \mathrm{s}$. To maximize payloads for such missions, the propellant exhaust velocity must be comparable to the required mission velocity, or most of the rocket mass will be carried in the form of propellant. A number of advanced propulsion technologies have been proposed and investigated over the past several decades in an effort to meet these mission requirements. Recent concepts include high energy density chemical propellants, nuclear thermal and nuclear electric thrusters, fusion vehicles, and antimatter annihilation engines. While each concept has merit, each also suffers from apparent performance or feasibility issues.
High energy density chemical fuels could provide an increase of 10 to 100 seconds in specific impulse over current chemical propulsion systems, ${ }^{1}$ which would significantly improve launch vehicle performance but is still too low to meet future deep space mission requirements. Advanced nuclear thermal engines can provide specific impulse values approaching $1000 \mathrm{~s},{ }^{2}$ an improvement over chemical systems but still not optimum for deep space exploration. Nuclear electric propulsion, in which a nuclear reactor is used to supply power for an electric propulsion system, can provide the required high specific impulse values and represents a promising avenue for further research and development. ${ }^{3.4}$ However, electric propulsion engines are typically low thrust devices that require continuous operation over a long period of time to achieve a required mission velocity. This is generally not an issue for orbit maneuvering and robotic exploration missions, where nuclear electric propulsion typically outperforms chemical and nuclear thermal engines in mission design studies. However, the performance of high power electrostatic and electromagnetic engines under consideration for piloted deep space exploration missions is currently limited by electrode erosion and associated thruster lifetime issues. ${ }^{4}$ Electrodeless plasma thruster concepts, ${ }^{5}$ in which radio and microwave frequencies are used to generate and heat a plasma propellant, have been investigated to alleviate the problems associated with electrode erosion, but to date the plasma densities and temperatures produced by these devices are insufficient to meet the thrust and specific impulse requirements for deep space exploration.

Fusion-based engines, in which a hot, dense plasma is ignited and sustained by controlled thermonuclear fusion reactions, appear to provide near-optimum performance values for fast interplanetary and deep space missions of interest. ${ }^{6}$ The primary reactor designs investigated for spacecraft propulsion include the plasma torus, magnetic mirror, laser and particle beam inertial confinement fusion, and dense plasma focus systems. ${ }^{7-9}$ However, even though fusion reactors have been under continuous development for several decades, an enormous amount of research and development remains before sustained fusion will be achieved. Even more exotic than fusion thrusters are engine designs based on antimatter annihilation, in which energetic antiproton annihilation byproducts are 
either directly exhausted for thrust or are confined and used to heat a propellant. Antiproton-based engines have received considerable attention over the past few years, and although a number of potentially useful thruster designs have emerged, they are constrained by the tremendous difficulty and expense associated with the production and storage of significant amounts of antiprotons. $^{10-13}$

In summary, the broad range of mission characteristics and propulsion concepts outlined above highlight a number of requirements that must be satisfied by propulsion systems used on future piloted deep space missions. Moderate to high specific impulse values are required to maximize the payload mass fraction, which effectively eliminates chemical engines as primary deep space propulsion systems. Electric propulsion engines can provide the necessary specific impulse values, but electrode erosion may limit thruster lifetime and place unwarranted constraints on future mission options. This suggests that electrodeless plasma thrusters would be good candidates for deep space missions, but current electrodeless systems cannot produce the proper combination of plasma density and temperature for piloted HEDS missions. Electrodeless fusion-based systems offer high plasma densities and high temperatures, but controlled fusion for either power or propulsion is still decades away. Deep space mission requirements call for a robust electrodeless thruster that can generate, heat, and expel high-density plasma with a specific impulse that optimizes the spacecraft mass ratio for a given mission $\Delta \mathrm{V}$. A candidate propulsion system with the potential to meet these requirements is the high power theta-pinch plasma thruster. Although a number of key issues remain to be resolved, a thetapinch design could bridge the gap between current high power electric propulsion systems and the more exotic fusion and antimatter-based thrusters of the future, enabling new and revolutionary capabilities for piloted deep space exploration.

\section{THETA-PINCH CONCEPT}

The theta-pinch thruster concept is derived from the experimental theta-pinch devices investigated during the early years of controlled fusion research. ${ }^{14-17}$ The early theta-pinch systems consisted of an insulating, cylindrical discharge chamber, open at each end, surrounded by a single-turn coil, as shown in Figure 1. The single-turn coil is attached to a high-energy capacitor bank and high voltage switch. Neutral gas is injected into the chamber, and the outer gas layers are partially ionized by either a brief current pulse sent through the discharge coil or through radio-frequency heating by antennas located outside of the discharge chamber. The main capacitor bank is then discharged to provide a large transient current in the single-turn coil surrounding the discharge chamber. The rapidly rising current in the coil creates a time-varying longitudinal magnetic field within the chamber, which in turn induces an azimuthal current in the preionized plasma sheath via Faraday's law of induction. The sheath current interacts with the axial magnetic field produced by the coil to generate a radially inward Lorentz force on the plasma ions and electrons. These particles move inward toward the axis of the chamber, and through collisions sweep the other gas particles along in a "snowplow" effect. The partially ionized gas is radially compressed at a speed greater than the local speed of sound, creating a radial shock wave characteristic of irreversible heating processes. Compression continues until the kinetic pressure of the shock-heated plasma balances the magnetic pressure of the axial magnetic field. Radial pressure balance is generally achieved within a fraction of a microsecond, at which point the shock heating is complete. The pulsed current sent through the coil has a rise time much longer than a microsecond, however, and as the current in the coil continues to increase so does the axial magnetic field strength. The increasing magnetic pressure produced by the increasing field continues to compress and heat the plasma until the peak current is reached, typically within a few microseconds. The axial magnetic field that heats the plasma also serves to provide radial confinement, which prevents the plasma from contacting the walls of the discharge chamber. The plasma is free to flow along axial magnetic field lines, however, and it quickly escapes from both ends of the discharge chamber.

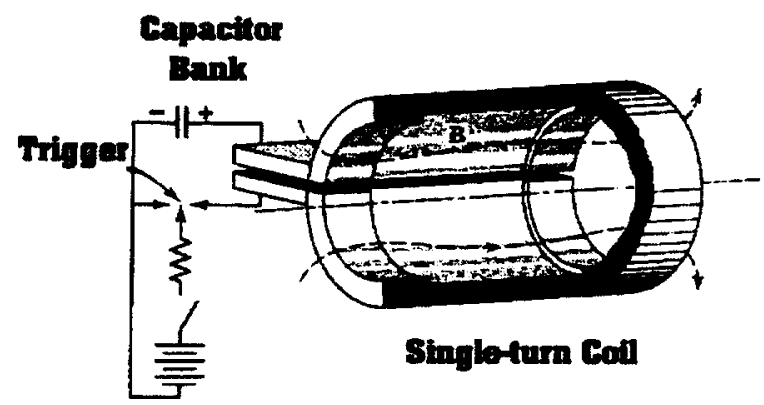

Figure 1. Theta-Pinch Schematic. ${ }^{18}$

Because the plasma escapes equally from both ends of the discharge chamber, a simple open-ended thetapinch cannot provide net thrust. The thruster concept investigated during the NIAC Phase I research program retains the basic simplicity of the theta-pinch discharge, but abrogates the symmetry of the standard theta-pinch geometry by placing a superconducting magnetic field coil at the upstream end of the chamber. The superconducting magnet acts as a charged particle mirror, reflecting the axial plasma flow from the 
upstream end of the chamber, back along the axial magnetic field lines and out of the open downstream end of the chamber to produce thrust.

As might be expected, several issues must be resolved to determine whether a pulsed, asymmetric theta-pinch can be made into an effective plasma thruster. This paper summarizes the results of a preliminary effort to model the plasma temperatures and densities needed to produce useful combinations of thrust and specific impulse, analyze the magnetic field strengths and discharge bank energies required for adiabatic plasma compression and heating, and provide realistic estimates of the total efficiency of a mirrored thetapinch system operated as a high-power pulsed plasma rocket. Although a number of issues remain to be investigated, such as the growth of plasma instabilities and plasma detachment from magnetic field lines, the initial results suggest that a scaled theta-pinch thruster operated with an upstream magnetic mirror could be an enabling propulsion technology for piloted deep space exploration, providing high average thrust at specific impulse values comparable to current electric propulsion engines.

\section{ANALYTIC THETA-PINCH MODEL}

Theta-pinch experiments typically consist of two phases: rapid radial plasma compression by a driving magnetic field, followed by the loss of the radially confined plasma along axial magnetic field lines. Radial plasma diffusion is orders of magnitude less than axial plasma flow losses in theta-pinch machines, allowing radial plasma diffusion to be neglected in the analytic model. In the absence of shocks, the initial radial compression is a reversible process and the adiabatic relations for pressure and temperature can be employed to describe the compression phase. In addition, radial compression of the plasma is accomplished on a time scale much smaller than the total plasma confinement time, and the total particle inventory (ions and electrons) can safely be assumed to remain constant during compression.

\section{Compression}

Based on these approximations, the change in plasma pressure due to compression by an external, timevarying magnetic field, $B_{0}$, is:

$$
\overline{\mathrm{P}}(\mathrm{t})=\frac{\mathrm{B}_{0}^{2}(\mathrm{t})}{2 \mu_{0}}
$$

where $\mu_{0}$ is the permeability of free space, $\bar{P}$ is the radially averaged plasma pressure, and induced magnetic fields within the plasma have been neglected.
During adiabatic compression, the radius, $r$, of the plasma changes according to the relation:

$$
\frac{\bar{P}(t)}{P_{0}}=\left(\frac{r_{0}}{r(t)}\right)^{10 / 3}
$$

where $r_{0}$ is the initial plasma radius and $P_{0}$ is the initial plasma pressure. Given the initial plasma radius, initial pressure, and average pressure. Equation 2 can be inverted to find the time-dependent plasma radius during compression. The average plasma number density, expressed as particle number per unit volume, is just the initial number of plasma particles, $\mathrm{N}_{0}$, divided by the time-varying volume of the compressing plasma column:

$$
\bar{n}(t)=\frac{N_{0}}{\pi r^{2}(t) L}
$$

where $\vec{n}$ is the average plasma number density and $\mathrm{L}$ is the length of the plasma column. The initial particle inventory, $\mathrm{N}_{0}$, can be determined from the initial plasma conditions:

$$
N_{0}=\frac{P_{0}}{k T_{0}}\left(\pi r_{0}^{2} L\right)
$$

where $k$ is Boltzmann's constant and $T_{0}$ is the initial plasma density in degrees- $K$. The column-averaged temperature of the plasma during compression, $\bar{T}$, is determined from the ideal gas equation:

$$
\bar{T}(t)=\frac{\bar{P}(t)}{k \bar{n}(t)}
$$

Given the discharge chamber length, initial plasma radius, initial pressure, initial temperature, and applied magnetic field history, the corresponding plasma pressure, radius, number density, and temperature during compression can be determined from the above set of self-consistent equations.

\section{Post Compression}

The plasma stops its radial compression once the applied magnetic field has reached its maximum value. In most theta-pinch experiments, the driving magnetic field is crow-barred at this point to sustain the axial field and keep the plasma radially confined for as long as possible. The post-compression part of this numerical theta-pinch simulation follows the analysis of Stover et al., ${ }^{19.20}$ who derive a simple end-loss model for plasma flow from open-ended theta-pinch devices. The post-compression plasma pressure is given by: 


$$
\bar{P}=\frac{B_{0}^{2}}{2 \mu_{0}}-\frac{B_{i}^{2}}{2 \mu_{0}} \approx \frac{B_{i}^{2}}{2 \mu_{0}}
$$

where again $B_{i}$ represents internal magnetic fields induced within the plasma column as a result of compression, and $B_{0}$ represents the time-dependent axial magnetic field. The effect of an internal magnetic field is to decrease the net pressure applied by the external axial magnetic field, resulting in less plasma compression. For the collisional, relatively low temperature plasmas of interest in this study, the induced magnetic fields are typically much smaller $(<10 \%)$ than the driving magnetic fields, hence internally generated magnetic fields are neglected in this analysis.

The internal energy of the plasma ions, $E_{i}$, is:

$$
E_{i}=\frac{3}{2} \bar{n} k \bar{T}\left(\pi r^{2} L\right)
$$

and the time rate of change of the ion internal energy is given by:

$$
\frac{\partial E_{i}}{\partial t}=-\varepsilon \frac{\partial N}{\partial t}-\bar{P} \frac{\partial A}{\partial t}-\frac{E_{i}}{\tau_{t h}}
$$

where $\mathrm{A}$ is the plasma column cross sectional area, $\tau_{\text {th }}$ is the ion thermal conduction time, and $\varepsilon$ is the average energy loss per particle due to the axial flow of particles from the plasma column, equal to $5 / 2 T$ for a collisional plasma. The first term on the right hand side thus represents the loss of energy due to plasma particles flowing from the chamber, the second term represents the work done on the plasma due to the compression of the plasma cross sectional area by the driving magnetic field, and the third term represents heat transfer by ion thermal conduction across the end of the plasma column.

The time dependent loss of particles from the chamber is given by:

$$
\frac{\partial N}{\partial t}=-\frac{N}{\tau_{c o n}}
$$

where $\tau_{\text {con }}$ is the particle confinement time. Based on a study of theta-pinch end-loss data, Stover et al. define the particle confinement time as:

$$
\tau_{c o n}=\frac{L}{2}\left(\frac{m_{i}}{2 k \bar{T}}\right)^{1 / 2} \chi
$$

where $m_{i}$ is the ion mass and $\chi$ is an empirical end loss parameter, approximately equal to 2.5 for collisional theta-pinch machines. The factor of $(L / 2)$ in the above equation results from the loss of plasma from both ends of the theta-pinch device.

Note that the above equations are not appropriate for modeling hot collisionless plasmas, where separate electron and ion temperatures and additional plasma transport properties must be taken into account. However, for the lower temperature collisional plasmas of interest in the theta-pinch thruster, the equations provide a self-consistent technique for analyzing time dependent theta-pinch behavior during radial compression and subsequent end-loss.

\section{Comparison with Experiment}

To determine the accuracy of the numerical model, comparisons were made with the Scylla I-C theta-pinch machine. ${ }^{19-21}$ The Scylla I-C consists of a $1-m$ long single turn coil that surrounds a $0.038-\mathrm{m}$ diameter discharge chamber which is open at both ends. The driving magnetic field for the Scylla-IC device is shown in Figure 2 below.

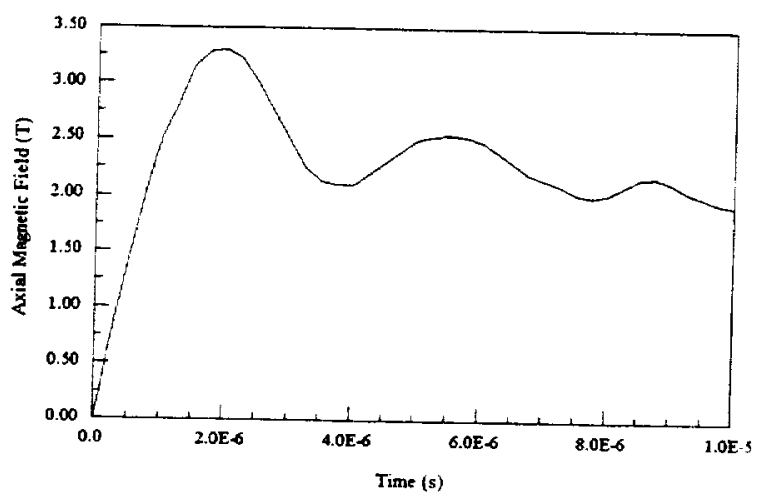

Figure 2. Driving field for Scylla-IC theta-pinch. ${ }^{19}$

The analytic model was used to predict the plasma number density and temperature of the Scylla I-C pinch as a function of time. The initial chamber pressure was 100 -mTorr, the gas was deuterium, and the preionization temperature was approximately $1-\mathrm{eV}$ $\left(1.16 \times 10^{4} \mathrm{~K}\right)$. The predicted column-average plasma number density is compared to the experimental centerline number density in Figure 3.

The analytic model accurately predicts the peak plasma number density as a function of time, and does a reasonable job of reproducing the experimental values at later times in the simulation. To achieve this fit, an additional assumption was made that the ratio of kinetic to magnetic field pressure is approximately 0.7 (plasma 
$\beta \approx 0.7$ ). This assumption derives from the experimental measurement of internal magnetic field lines trapped within the plasma during compression, which is not explicitly calculated in the code. Diamagnetic loop measurements made during the Scylla-IC experiments indicate that typical $\beta$ values ranged from 0.7 to 0.8 , and the simulation results are fairly insensitive within that range.

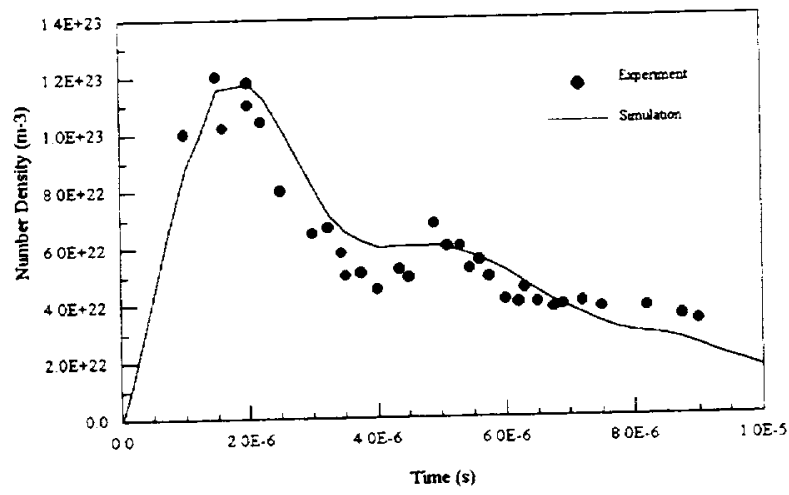

Figure 3. Scylla-IC plasma number density vs. time.

The following figure compares the predicted columnaverage plasma temperature with the experimentally measured centerline plasma temperature:

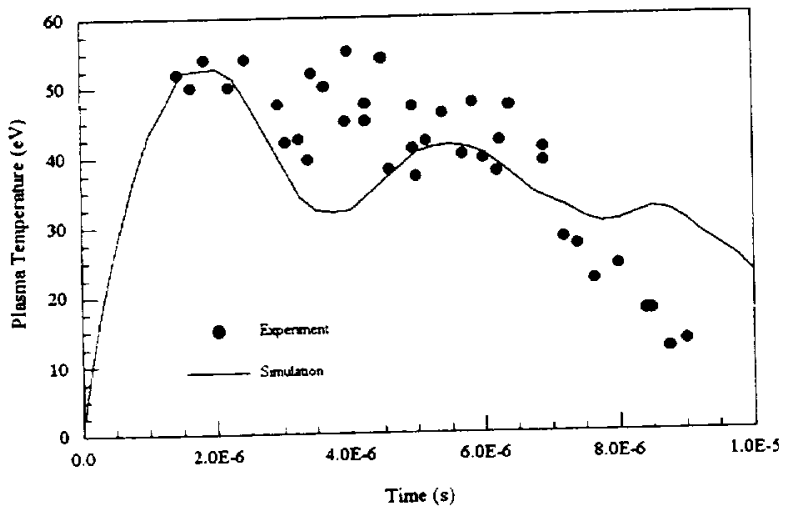

Figure 4. Scylla-IC plasma temperature vs. time.

The predicted temperature at $2 \mu$ s exactly reproduces the measured plasma temperature at peak compression, but the predicted dip in plasma temperature at approximately $4 \mu \mathrm{s}$ is not observed in the experimental data. The predicted temperatures are also about $50 \%$ higher than the experimentally measured values at late confinement times. As discussed by Stover, ${ }^{19}$ the latter effect may be due to the arrival of rarefaction waves from the ends of the theta-pinch, which is not modeled in this simple analysis. The simulated temperature dip at $4 \mu$ s appears to follow the driving magnetic field, and it is not apparent why the experimental data does not also show the same decrease in centerline temperature.
The effect might be explained by differences between the uniform plasma model used in the above set of equations and the actual experimental plasma profile, which is more likely a Gaussian distribution around the centerline where the temperature is measured. These effects cannot be modeled using the simple set of equations above, and await a more detailed examination with a 2-D numerical simulation currently under development.

\section{THETA PINCH THRUSTER MODEL}

In general, the analytic model reproduces the columnaveraged plasma densities and temperatures measured for the experimental Scylla-IC theta-pinch, providing some confidence that the code can be used as a predictive tool to evaluate theta-pinch thruster performance. As previously noted, the simulation is only valid for collisional plasmas, and can't be used to model low density, high temperature plasma pinches. This is not anticipated to be a serious limitation, however, since the theta-pinch thruster operates in the collisional plasma regime.

To predict the performance of a theta-pinch thruster, some additional equations for exhaust velocity, specific impulse, and impulse bit must be added to the simulation. The average plasma exhaust velocity, $V_{e}$, and corresponding specific impulse, $I_{\text {sp, can be }}$ estimated using the root-mean-square formula for plasma velocity:

$$
\begin{gathered}
V_{e}(t)=\sqrt{3 k \bar{T} / m_{i}} \\
I_{s p}=\frac{V_{e}}{g}
\end{gathered}
$$

where $\mathrm{k}$ is Boltzmann's constant, $\bar{T}$ is the average temperature of the plasma distribution, and $m_{i}$ is the ion mass. The time-dependent plasma mass flow rate, $\dot{m}$, can be calculated from the time evolution of the plasma particle number, $N(t)$ :

$$
\dot{m}=\frac{d m}{d t}=m_{i}\left(\frac{d N}{d t}\right)
$$

The impulse bit, $\mathrm{I}_{\text {bit }}$, delivered by the plasma exhaust is given by:

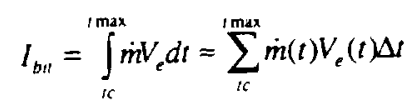

where the integration and summation times extend from the time at maximum compression (tc), when the plasma begins to move axially along magnetic field 
lines, to the maximum plasma confinement time (tmax), defined either by the axial loss of the plasma from the discharge chamber or by the loss of radial plasma confinement due to the termination of the driving magnetic field. Multiplying the impulse bit by the pulse repetition rate provides a value for the timeaveraged thrust provided by the theta-pinch engine.

In addition to specific impulse and impulse bit, a parameter of interest for electric propulsion systems is the total thrust efficiency, defined as the ratio of directed propellant kinetic energy to initial stored energy. In systems with low thrust efficiency, a significant amount of the discharge power will end up deposited in the current carrying support structure, which in the case of the theta-pinch thruster is the discharge coil. An estimate can be made of the pulsed thruster efficiency, $\eta$, using the equation:

$$
\eta=\frac{\frac{1}{2} \Delta m \bar{V}_{e}^{2}}{E_{\text {bank }}} \times 100 \%
$$

where $\Delta m$ is the total propellant mass ejected during the pulsed discharge, $\bar{V}_{e}$ is the average plasma exhaust velocity, and $E_{\text {bank }}$ is the capacitor bank energy discharged during the pulse. The capacitor bank energy required to compress and heat a theta-pinch plasma can be estimated using an expression derived by Kolb: ${ }^{22}$

$$
T_{\max } \approx T_{0}\left(\frac{r_{c}}{r_{0}}\right)\left(\frac{E_{\text {bank }}}{E_{0}}\right)
$$

where $T_{\max }$ is the compressed plasma temperature, $T_{0}$ is the initial preionization plasma temperature, $r_{0}$ and $r_{c}$ are the initial and final plasma radii, respectively, $E_{\text {bank }}$ is the total bank energy used to drive the compression, and $E_{0}$ is the total initial energy contained in the preionized plasma. Rearranging Equation 16 yields an expression for the required bank energy as a function of plasma temperature:

$$
E_{\text {bank }}=E_{0}\left(\frac{r_{0}}{r_{c}}\right)^{2}\left(\frac{T_{\max }}{T_{0}}\right)^{2}
$$

Comparison with theta-pinch experiments indicates the capacitor bank energy estimate is accurate to within roughly $10 \%$ for collisional devices. ${ }^{114-17}$ For a given mass injection and power per pulse, the efficiency predicted by Equation 15 for a single pulse is equivalent to the efficiency that would be observed under repetitively pulsed thruster operation.

\section{PERFORMANCE PREDICTIONS}

The modified that-pinch model was used to examine the performance of a large theta-pinch thruster design over a variety of discharge pressures and pulse periods. The size of the thruster discharge chamber was increased from the $0.019-\mathrm{m}$ radius, $1-\mathrm{m}$ long Scylla-IC thetapinch design to a 1-meter radius, 10-meter long cylindrical chamber. The pulse period was initially increased from $10-\mu \mathrm{s}$ to $100-\mu \mathrm{s}$, and the form of the driving magnetic field was changed from the Scylla-IC field shown in Figure 2 to the more rectangular pulse shape shown in Figure 5. Two axial magnetic field strengths were evaluated, corresponding to peak field values of $1-T$ and $2-T$, respectively. The peak field strength in each case was decreased by $10 \%$ over the pulse period to mimic realistic rectangular current waveforms. Hydrogen propellant was again assumed, with an initial preionization temperature of $1.0-\mathrm{eV}$. Based on the Scylla-IC results, the presumed initial chamber pressures ranged from a low of 500 -mTorr $\left(6.6 \times 10^{-4} \mathrm{~atm}\right)$ to a high of 100 -Torr $\left(10^{5}\right.$-mTorr, or $0.13 \mathrm{~atm})$.

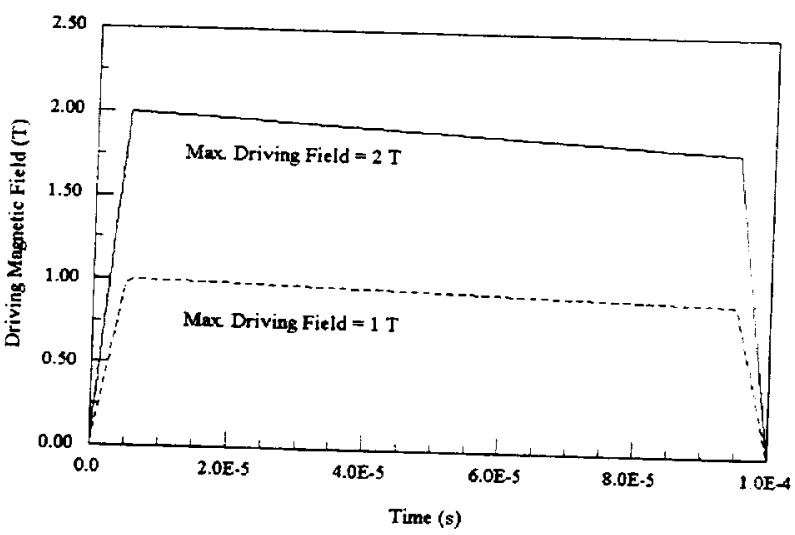

Figure 5. Driving magnetic fields for modified thruster geometry, $10^{-4} \mathrm{~s}$.

\section{Dependence on Initial Pressure}

Figure 6 shows the predicted compression temperatures as a function of initial chamber pressure for each driving magnetic field. For an axial magnetic field strength of $1-T$, the maximum plasma temperature reached during compression ranges from $16-\mathrm{eV}$ for an initial chamber pressure of 500 -mTorr to a low of around $2-\mathrm{eV}$ for a 100 -Torr initial chamber pressure. The 2-T magnetic field is able to compress the plasmat to higher temperatures, producing compressed temperature values of $28-\mathrm{eV}$ to $3.5-\mathrm{eV}$ over the same pressure range. Specific impulse values corresponding to these compression temperatures are shown in Figure 7 as a function of initial chamber pressure. For low chamber pressures, the average specific impulse 
produced by the 1-T driving field is around $5,600 \mathrm{~s}$, decreasing to $1,900 \mathrm{~s}$ as the initial chamber pressure is increased. For the 2-T magnetic field, the specific impulses range from a high of $7,000 \mathrm{~s}$ at an initial chamber pressure of $500-\mathrm{mT}$ orr to a low of $2,500 \mathrm{~s}$ at an initial pressure of 100-Torr.

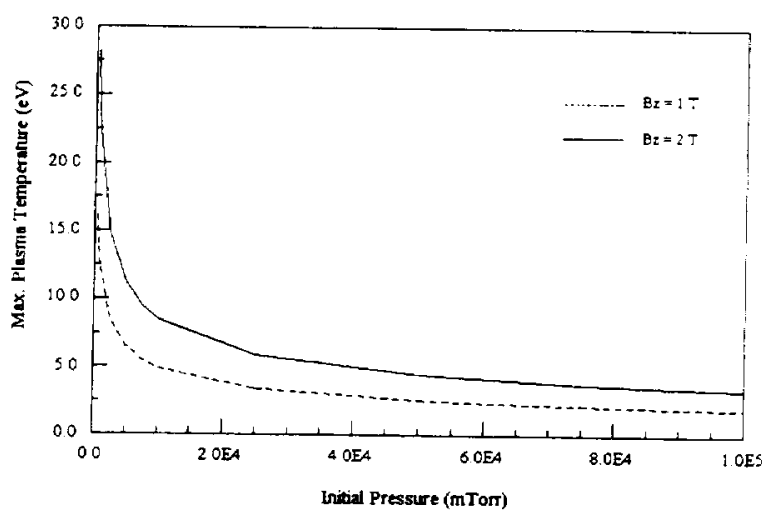

Figure 6. Maximum plasma temperature vs. initial chamber pressure.

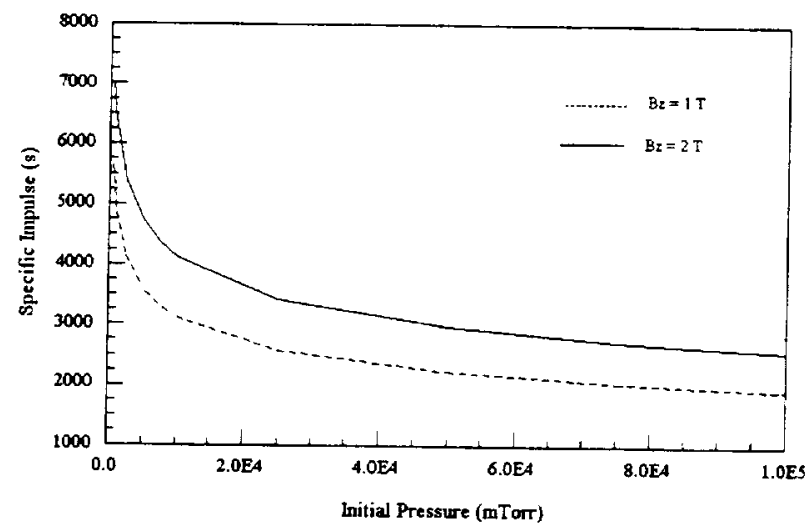

Figure 7. Average specific impulse vs. initial chamber pressure.

The impulse-bit delivered by the modified theta-pinch thruster is shown in Figure 8 for the different driving fields as a function of the initial chamber pressure. For the 1-T magnetic field, the impulse-bit delivered by the thruster ranges from $0.3 \mathrm{~N}-\mathrm{s}$ for the lowest initial chamber pressure to slightly over $7 \mathrm{~N}$-s for higher initial chamber pressures. For the 2-T field, the impulse-bit ranges from a low of around $0.4 \mathrm{~N}-\mathrm{s}$ to a high of $12 \mathrm{~N}$-s over the same pressure range.

For a pulse repetition rate of $100-\mathrm{Hz}$, the thruster operated with a pulsed 2-T driving field and an initial chamber pressure of 100-Torr could provide an average thrust of nearly $1,200 \mathrm{~N}$ at a specific impulse of around $2,500 \mathrm{~s}$, a unique combination that cannot be produced with current chemical or electric propulsion systems.

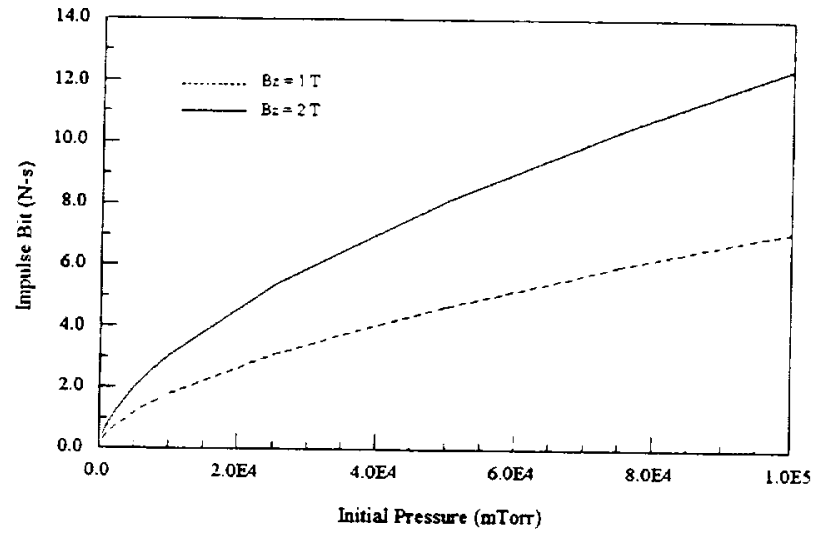

Figure 8. Impulse-bit vs. initial chamber pressure.

Reducing the initial chamber pressure allows the thruster to operate at a higher specific impulse, but reduces the average thrust. For example, with an initial chamber pressure of 10-Torr the same thruster could produce an average thrust of approximately $300 \mathrm{~N}$ at a specific impulse of around $4,100 \mathrm{~s}$. Further reductions in the initial chamber pressure would further increase the average specific impulse, but the delivered thrust becomes comparable to or less than the thrust provided by current electric propulsion systems. At an initial chamber pressure of 1-Torr, the thruster operated at $100-\mathrm{Hz}$ with a $2-\mathrm{T}$ axial field would produce an average thrust of $70-\mathrm{N}$ at a specific impulse of $6,300 \mathrm{~s}$, a propulsion regime that can be achieved with present high-power magnetoplasmadynamic thrusters operated with lithium or hydrogen propellants. ${ }^{4}$

Although the average thrust and specific impulse produced by the pulsed theta-pinch thruster at higher initial chamber pressures is of potential interest for deep space mission applications, the predicted efficiency of the engine is still quite poor. Figure 9 shows the efficiency of the $1-\mathrm{m}$ radius, $10-\mathrm{m}$ long thruster operated with 1-T and 2-T driving magnetic fields as a function of initial chamber pressure. For the 1-T field, the efficiency ranges from $1.4 \%$ at 500 -mTorr, peaks at $2.6 \%$ for an initial chamber pressure of 10-Torr, and then declines to less than $1 \%$ at the higher chamber pressures. For the 2-T case, the efficiency increases from just under $1 \%$ for a low 500-mTorr chamber pressure to around $2.7 \%$ at 50 -Torr, and then decreases as the chamber pressure is increased further.

The decrease in efficiency with increasing chamber pressures is ultimately due to the limited compression time provided by the discharge coil. As the initial chamber pressure is increased, the amount of propellant mass injected into the chamber increases but the compressed plasma temperature and exhaust velocity decrease. The total amount of mass expelled along the 
axial field lines also increases as the initial chamber pressure is increased, but the relative fraction of mass expelled vs. mass injected into the chamber actually decreases at higher pressures due to the lower exhaust velocity, as depicted in Figure 10. For the thruster operated with a $2-\mathrm{T}$ magnetic field, roughly $30 \%$ of the injected mass is expelled from the chamber at low initial pressures, while only $11 \%$ of the injected mass is expelled for high initial chamber pressures. For the 1-T driving field, the fraction of mass used ranges from $23 \%$ at low pressure to around $9 \%$ at high pressure.

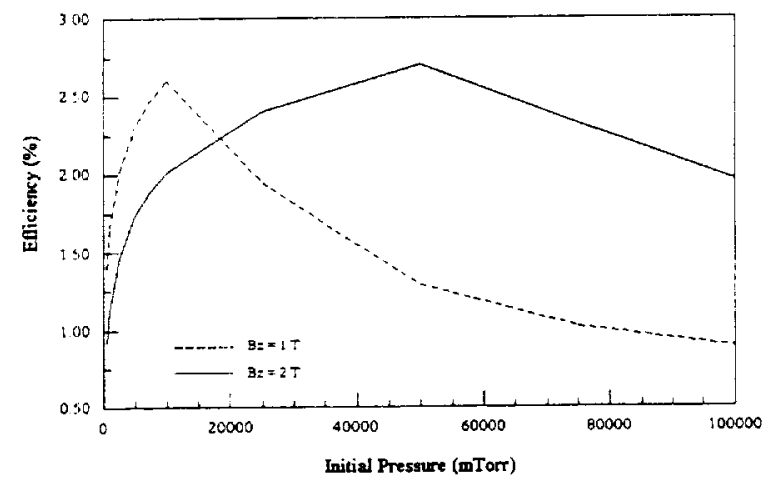

Figure 9. Thruster efficiency vs. initial chamber pressure.

The mass that remains in the thrust chamber at the end of the pulse period will expand radially as the energy in the discharge coil diminishes, and will presumably return to the lower initial preionization temperature since the compression process is adiabatic. While this recovery may be beneficial in terms of minimizing the addition of preionization energy, the reduced fraction of expelled mass that occurs at the higher chamber pressures limits the plasma kinetic energy delivered during a pulse. In contrast, the total discharge energy delivered during the pulse depends on the total mass injected into the chamber, which is linearly proportional to the initial chamber pressure, and on the square of the ratio of final to initial plasma temperature. Thus the growth in kinetic energy of the plasma with increasing chamber pressure is eventually overshadowed by the increase in the discharge energy, and the thrust efficiency, not large to begin with, decreases.

The modified theta-pinch thruster thus appears to offer a useful combination of thrust and specific impulse, but the efficiency at this point is too low for the device to be practical. For the $1-\mathrm{m}$ radius thruster operating with a 2-T field, the "optimum" efficiency of $2.7 \%$ occurs for an initial chamber pressure of 50-Torr. From Figure 6 , the compressed plasma temperature corresponding to this initial chamber pressure is approximately $4.5-\mathrm{eV}$.

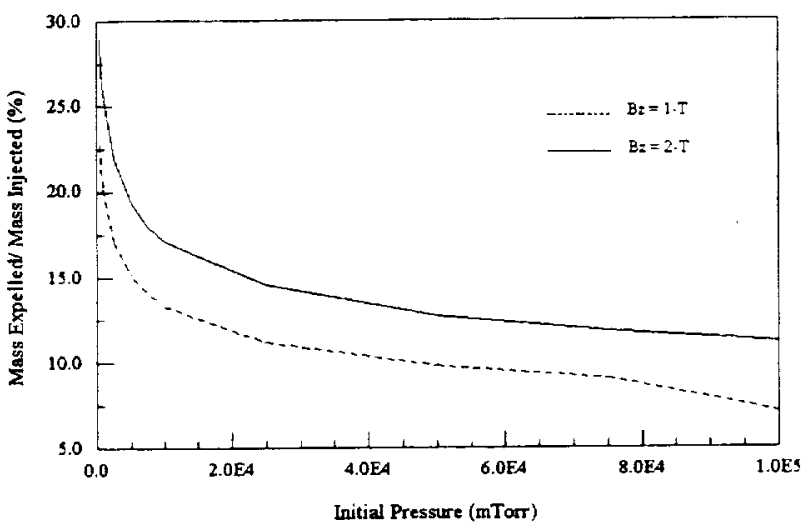

Figure 10. Fraction of propellant mass expelled vs. initial chamber pressure.

The initial preionization temperature is assumed to be $1-\mathrm{eV}$, yielding an initial plasma energy of $2.1 \times 10^{5} \mathrm{~J}$ (Equation 7). The total bank energy, calculated using Equation 17 , is $4.2 \times 10^{6} \mathrm{~J}$; for a $100-\mathrm{Hz}$ repetition rate, the average power delivered by the bank is around $4.2 \times 10^{8}$ Watts $(420-\mathrm{MW})$. If the thruster operates at $2.7 \%$ efficiency, then roughly $1.1 \times 10^{7}$ Watts appears in the plasma exhaust and nearly $4.1 \times 10^{8}$ Watts will appear somewhere in the system as heat that will have to be dissipated. Some of this waste power can be recovered to charge the capacitor banks and perform spacecraft housekeeping duties, but a significant portion will have to be radiated into space to keep the engine walls from melting. Improvements in thetapinch thruster performance will thus require a significant increase in thrust efficiency. One possible technique for increasing the efficiency is to increase the amount of propellant mass expelled during the pulse; since the total mass injected into the chamber will be compressed and heated, increasing the amount of mass exhausted from the thruster would improve the total impulse without significantly increasing the discharge energy. The amount of mass expelled increases linearly with the pulse duration, so if the pulse could be lengthened, the amount of mass exhausted from the thruster would be increased and the efficiency improved. This option is considered in the next section.

\section{Dependence on Discharge Duration}

To investigate potential improvements in thruster performance with longer pulse periods, the analytic model was used to simulate a $1-\mathrm{m}$ radius, $10-\mathrm{m}$ long thruster operated with hydrogen propellant at a preionization temperature of $1-\mathrm{eV}$ and a pulse duration of $10^{-3} \mathrm{~s}$. Driving fields of 1-T and 2-T were again assumed, with the magnetic field distributions shown in Figure 11. 


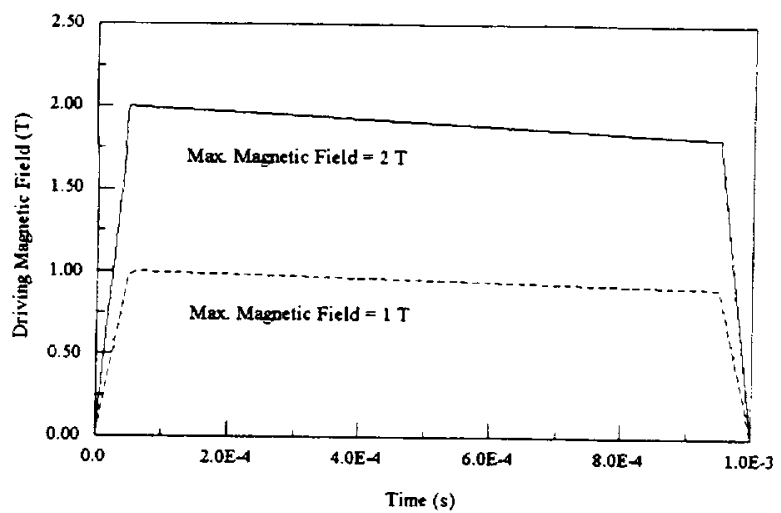

Figure 11. Driving magnetic fields for modified thruster geometry, $10^{-3} \mathrm{~s}$.

The maximum plasma compression temperatures are plotted in Figure 12 as a function of the initial chamber pressure for each magnetic field strength. For the extended duration simulations, the initial chamber pressure was varied from a low of 500-mTorr $\left(6.6 \times 10^{-4}\right.$ atm) to a high of 500 -Torr $(0.67 \mathrm{~atm})$. The maximum compression temperatures are identical to the compression temperatures reached during the shorter $10^{-4} \mathrm{~s}$ discharge period (Figure 6), which is expected since the driving fields reach the same peak values in each case. For the 1-T magnetic field, the compression temperature at the lowest initial chamber pressure peaks at around 16-eV, decreasing to about $6.7-\mathrm{eV}$ at the highest simulated chamber pressure. For the 2-T driving field, the compression temperature reaches 28 $\mathrm{eV}$ at the lower chamber pressure and decreases to 2.6$\mathrm{eV}$ at the higher initial chamber pressure.

The average specific impulse for each case is shown in Figure 13. The specific impulse values achieved with the longer pulse duration are slightly higher than the average specific impulses provided by the shorter discharge times (Figure 7). This is primarily due to the form of the driving field, in which the maximum field is reduced by $10 \%$ over the duration of the pulse to mimic a realistic rectangular current pulse. As a result, the magnetic field value used in the simulation drops off more quickly for shorter pulse periods. For example, the 1-T field shown in Figure 5 changes from a peak value of $1-\mathrm{T}$ at $5 \times 10^{-6} \mathrm{~s}$ to $0.9-\mathrm{T}$ at $9.5 \times 10^{-5} \mathrm{~s}$, a drop of $10 \%$ in $9 \times 10^{-6}$ seconds. In contrast, the field shown in Figure 11 drops from a peak value of 1-T at $5 \times 10^{-5} \mathrm{~s}$ to $0.9-\mathrm{T}$ at $9.5 \times 10^{-4} \mathrm{~s}$, decreasing by $10 \%$ in $9 \times 10^{-4}$ seconds. The confining magnetic field therefore remains higher for a longer period of time in the longer pulse simulations, and the corresponding plasma temperature remains higher for a longer period as well. Because the specific impulse is related to the plasma temperature, the average specific impulse achieved with a longer confinement period is slightly higher than the specific impulse achieved with shorter duration pulses. This result is simply an artifice of the shapes assumed for the driving magnetic fields; if the fields were constant for each pulse duration period, the specific impulse values shown in Figures 7 and 13 would be identical.

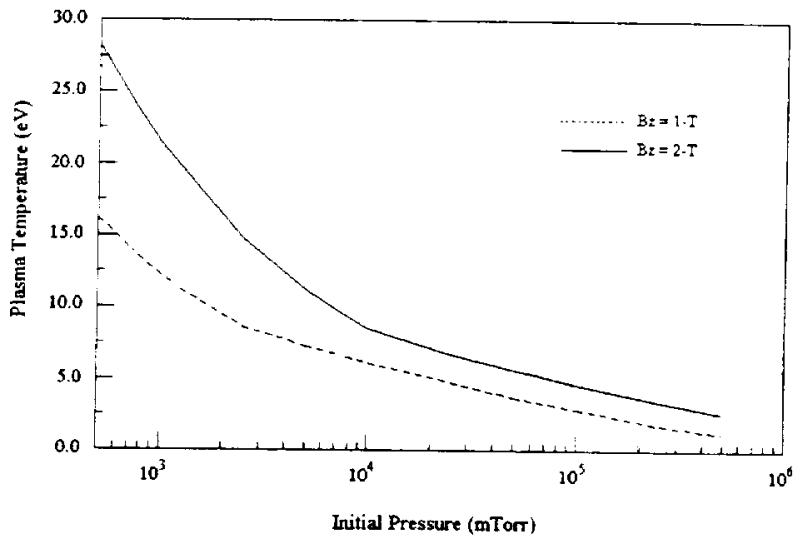

Figure 12. Maximum plasma temperature vs. initial chamber pressure.

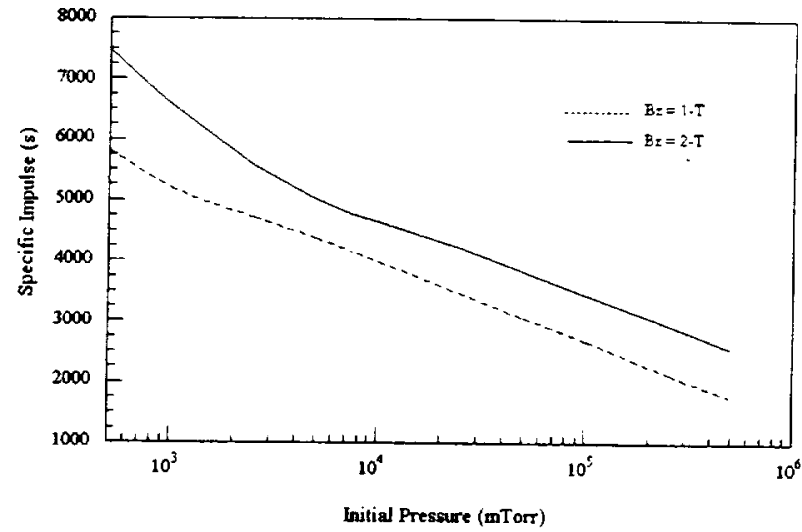

Figure 13. Average specific impulse vs. initial chamber pressure.

Figure 14 shows the impulse-bit delivered by the thruster using the longer pulse. The predicted impulsebits are substantially higher than the impulse-bits provided by the shorter duration discharges, increasing from slightly under $1 \mathrm{~N}$-s to over $190 \mathrm{~N}-\mathrm{s}$ for the 1-T driving field, and from $1 \mathrm{~N}$-s to around $330 \mathrm{~N}$-s for the 2-T driving field over the range of simulated chamber. The pulsed thruster efficiency corresponding to the longer duration discharge is shown in Figure 15 as a function of initial chamber pressure. The predicted efficiencies are substantially improved when the thruster is operated with a longer discharge period. For the 1-T driving field, a peak efficiency of about $15 \%$ occurs for an initial chamber pressure of around 50Torr. The thruster efficiency when operated with a 2-T driving field reaches $16 \%$ at an initial chamber pressure of around 100-Torr. The higher efficiencies are a 
consequence of better propellant mass utilization provided by the longer pulse duration.

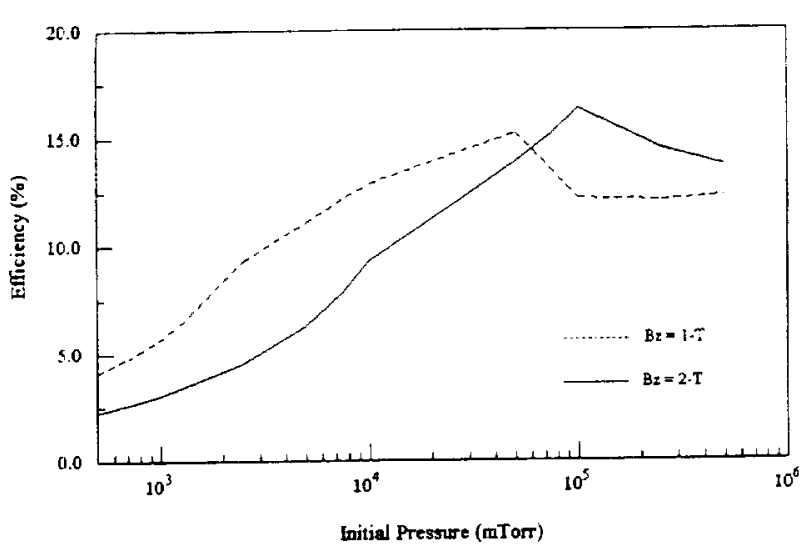

Figure 14. Impulse-bit vs. initial chamber pressure, $10^{-3} \mathrm{~s}$ pulse.

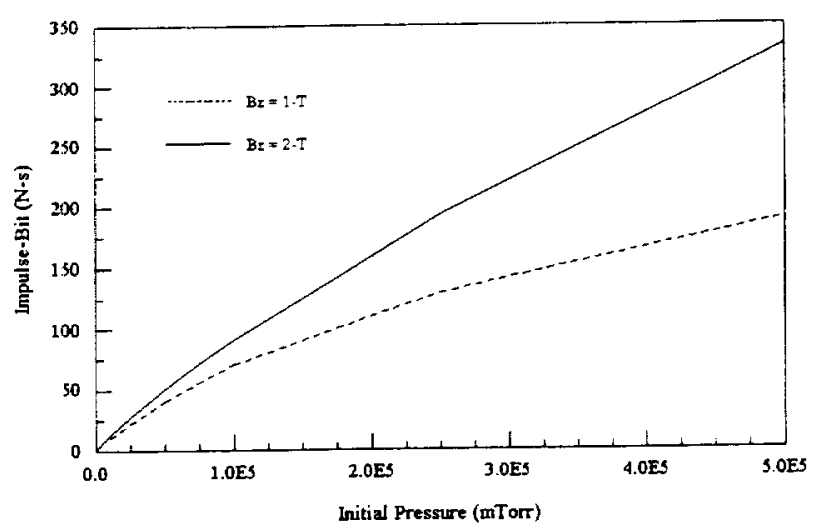

Figure 15. Efficiency vs. initial chamber pressure, $10^{-3} \mathrm{~s}$ pulse.

The fraction of propellant mass expelled compared to propellant mass injected remains fairly constant at around $60 \%$ over the full range of simulated chamber pressures for both the 1-T and 2-T driving fields, compared to the decreasing mass fractions observed with the short-duration pulses modeled in the previous section. While the predicted efficiencies are still lower than desired, they are within a factor of 2 of current high power magnetoplasmadynamic thrusters that operate at similar specific impulse but substantially lower thrust. ${ }^{4}$ By tailoring the magnetic field and optimizing the initial chamber pressure, there is some hope that the pulsed theta-pinch thruster efficiencies can be further improved.

The impulse-bit delivered by the theta-pinch engine is significantly higher than the corresponding impulse delivered by current plasma propulsion devices, such that even modest pulse repetition rates will provide large average thrust values. For example, a 1 -m radius, 10-m long theta-pinch thruster operated with hydrogen at a chamber pressure of 100-Torr produces an impulsebit of around $90 \mathrm{~N}-\mathrm{s}$ per pulse at an efficiency of $16 \%$. Assuming a pulse repletion rate of $100-\mathrm{Hz}$, the average thrust produced by the engine would be around 9,000 $\mathrm{N}$, with a predicted specific impulse of around 3,500 seconds. The discharge energy per pulse is predicted to be approximately $9 \times 10^{6} \mathrm{~J}$, for an average engine power of $9 \times 10^{8}$ Watts. Operating the engine at a lower pulse rep-rate of $10-\mathrm{Hz}$ reduces the average thrust to around $900-\mathrm{N}$ and the average on-board power to $90-\mathrm{MW}_{\mathrm{e}}$. These requirements are currently beyond our in-space power capabilities, but are not unreasonable for future space-based nuclear power systems.

\section{CONCLUDING REMARKS}

The analytic theta-pinch model was used to evaluate theta-pinch thruster performance for various chamber sizes, chamber pressures, and discharge periods. The trends in performance indicate that fairly long discharge times, on the order of $10^{-3}$ seconds, and fairly large discharge chambers, around $1-\mathrm{m}$ in radius and $10-\mathrm{m}$ long, are required for useful thruster operation. Depending on initial chamber pressures, the specific impulse of the thruster operated with a 2-T axial magnetic field varies from $7,500 \mathrm{~s}$ at 500 -mTorr to $2,500 \mathrm{~s}$ at 500 -Torr. The impulse-bit provided by the engine ranges from $1 \mathrm{~N}$-s to $330 \mathrm{~N}$-s over the same pressure range. The peak thruster efficiency is around $16 \%$, achieved for an initial chamber pressure of 100 torr. The impulse-bit and specific impulse at this operating point are $90 \mathrm{~N}-\mathrm{s}$ and $3,500 \mathrm{~s}$, respectively and the discharge energy per pulse is around $9 \times 10^{6} \mathrm{~J}$. For a pulse repetition rate of $10-\mathrm{Hz}$, the engine will deliver an average thrust of $900-\mathrm{N}$ at $3,500 \mathrm{~s}$ specific impulse. Operation at this rep-rate requires an on-board power capability of around $90-\mathrm{MW}$, and the low $16 \%$ thrust efficiency will require substantial power recovery and engine cooling capabilities. Nevertheless, the combination of thrust and specific impulse provided by the theta-pinch thruster makes it a unique concept among space propulsion systems, and further development should lead to an efficient design capable of performing the bold new exploration missions envisioned by the National Aeronautics and Space Administration.

\section{REFERENCES}

'Carrick, P. and S. Tam, (eds.), Proceedings of the High Energy Density Matter (HEDM) Contractor's Conference, USAF Phillips Laboratory Report PL-TR95-3039, June 1995. 
'Gunn, S., "Development of Nuclear Rocket Engine Technology", AIAA-89-2386, 25th Joint Propulsion Conference, Monterey, CA, July 1989.

${ }^{3}$ El-Genk, M. and Hoover, M. (eds), Nuclear Electric Propulsion Systems, Chapter 32 in Proceedings of the Tenth Symposium on Space Nuclear Power and Propulsion, AIP Conference Proc. 271, American Institute of Physics Press, New York, 1993.

${ }^{4}$ Myers, R., Mantenieks, M., and LaPointe, M., "MPD Thruster Technology," NASA TM-105242, Sep 1991.

SSercel, J., "Electron Cyclotron Resonance (ECR) Plasma Thruster Research," AIAA-88-2916, 24 th Joint Propulsion Conference, Boston, MA, July 1988.

${ }^{6}$ Shulze, N., "Fusion Energy for Space Missions in the 21 st Century," NASA TM-4298, Aug 1991.

${ }^{7}$ Williams, C., Borowski, S., Dudzinski, L., and Juhasz, A., "A Spherical Torus Nuclear Fusion Reactor Space Propulsion Vehicle Concept for Fast Interplanetary Travel," AIAA-98-3591, 34th Joint Propulsion Conference, Cleveland, OH, July 1998.

${ }^{8}$ Emrich, W., "Performance Optimization of the Gasdynamic Mirror Propulsion system," AIAA-983588, 34th Joint Propulsion Conference, Cleveland, OH, July 1998.

${ }^{9}$ Miley, G., Nadler, J., Temple, B., Bolt, S., and Kislev, H., "Critical Technology Demonstration of Plasma Focus Type MPD Thruster," USAF Phillips Laboratory Report PL-TR-92-3008, May 1992.

${ }^{10}$ Forward, R., "Antiproton Annihilation Propulsion," USAF Rocket Propulsion Laboratory Report AFRPL TR-85-034, Sept 1985.

${ }^{11}$ Cassenti, B., "High Specific Impulse Antimatter Rockets," AIAA-91-2548, 27th Joint Propulsion Conference, Sacramento, CA, June 1991.

${ }^{12}$ Gaidos, G., Lewis, R., Smith, G., Dundore, B., and Chakrabarti, S., "Antiproton-Catalyzed Microfission Fusion Propulsion Systems for Exploration of the Outer Solar System and Beyond," AIAA-98-3589, 34th Joint Propulsion Conference, Cleveland, OH, July 1998.

${ }^{13}$ LaPointe, M., "Antiproton Powered Propulsion with Magnetically Confined Plasma Engines," J. Propulsion and Power, I (5) 1991, pp. 749-759.
${ }^{14}$ Bodin, H. A. B., Green, T. S., Newton, A. A., Niblett, G. B. F., and Reynolds, J. A., "Plasma Containment and Stability in a Megajoule Theta-Pinch Experiment," Plasma Physics and Nuclear Controlled Fusion Research, Vol. 1, International Atomic Energy Agency, Vienna, 1966, pp. 193-222.

${ }^{15}$ Quinn, W. E., Little, E. M., Ribe, F. L., and Sawyer, G. A., "Stability and End Loss of a 3.5-MJ Theta-Pinch (Scylla-IV)," Plasma Physics and Nuclear Controlled Fusion Research, Vol. 1, International Atomic Energy Agency, Vienna, 1966, pp. 237-248.

${ }^{16}$ Bodin, H. A. B., McCartan, J., Newton, A. A., and Wolf, G. H., "Diffusion and Stability of High- $\beta$ Plasma in an 8-meter Theta-Pinch," Plasma Physics and Nuclear Controlled Fusion Research, Vol. II, International Atomic Energy Agency, Vienna, 1969, pp. 533-551.

${ }^{17}$ Hamm, J. J., Knoepfel, H., Krogler, H., Linhart, J. G., and Verbeek, R., "Very-High Density Theta-Pinch," Plasma Physics and Nuclear Controlled Fusion Research, Vol. II, International Atomic Energy Agency, Vienna, 1969, pp. 629-638.

${ }^{18}$ Rose, D. J. and Clark, M. C. Jr., Plasma and Controlled Fusion, MIT Press, Massachusetts Institute of Technology and J. Wiley \& Sons, Inc., New York, 1961, p. 382.

${ }^{19}$ Stover, E., "Computer Simulation of Plasma Behavior in Open-Ended Linear Theta Machines," U.S. Department of Energy Report DOE/ET/53018-6, April 1981.

${ }^{20}$ Stover, E., Klevans, E., and York, T., "Computer Modeling of Linear Theta-Pinch Machines," Phys Fluids, 21 (11), Nov 1978, pp. 2090-2102.

${ }^{21}$ McKenna, K. F. and York, T. M., "End Loss From a Collision Dominated Theta-Pinch Plasma," Phys Fluids, 20 (9), Sep 1977, pp. 1556-1565.

${ }^{22}$ Kolb, A. C., referenced in Rose, D. J. and Clark, M. C. Jr., Plasma and Controlled Fusion, MIT Press, Massachusetts Institute of Technology and J. Wiley \& Sons, Inc., New York, 1961, pp. 382-386. 
Public reporing burden for this collection of information is estimated to average 1 hour per response, including the time for reviewing instructions, searching existing data sources, Public reponting burden tor this collection gathering and maintaining the data needed, and completing and collection of

\begin{tabular}{l|l|l|} 
1. AGENCY USE ONLY (Leave blank) & 2. REPORT DATE & 3. REPORT TYPE AND DATES COVERED
\end{tabular}

4. TITLE AND SUBTITLE

August 2000

Theta-Pinch Thruster for Piloted Deep Space Exploration

6. AUTHOR(S)

Mike R. LaPointe

7. PERFORMING ORGANIZATION NAME(S) AND ADDRESS(ES)

Ohio Aerospace Institute

22800 Cedar Point Road

Brook Park, Ohio 44142

9. SPONSORING/MONITORING AGENCY NAME(S) AND ADORESS(ES)

National Aeronautics and Space Administration

Washington, DC 20546-0001
WU-632-6B-1C-00

NAG3-2230

8. PERFORMING ORGANIZATION

REPORT NUMBER

E-12404

10. SPONSORING/MONITORING AGENCY REPORT NUMBER

NASA CR-2000-210355

AIAA-2000-3365

11. SUPPLEMENTARY NOTES

Prepared for the 36th Joint Propulsion Conference and Exhibit cosponsored by AIAA, ASME, SAE, and ASEE, Huntsville, Alabama, July 17-19, 2000. Project Manager, Dhanireddy Reddy, Power and On-Board Propulsion Technology Division, NASA Glenn Research Center, organization code 5430, (216) 433-8133.

12a. DISTAIBUTION/AVAILABILITY STATEMENT 12b. DISTRIBUTION CODE

Unclassified - Unlimited

Subject Category: 20

Distribution: Nonstandard

This publication is available from the NASA Center for AeroSpace Information, (301) 621-0390.

13. ABSTRACT (Maximum 200 words)

A new high-power propulsion concept that combines a rapidly pulsed theta-pinch discharge with upstream particle reflection by a magnetic mirror was evaluated under a Phase I grant awarded through the NASA Institute for Advanced Concepts. Analytic and numerical models were developed to predict the performance of a theta-pinch thruster operated over a wide range of initial gas pressures and discharge periods. The models indicate that a $1-\mathrm{m}$ radius, $10-\mathrm{m}$ long thruster operated with hydrogen propellant could provide impulse-bits ranging from $1 \mathrm{~N}-\mathrm{s}$ to $330 \mathrm{~N}$-s with specific impulse values of $7,500 \mathrm{~s}$ to $2,500 \mathrm{~s}$, respectively. A pulsed magnetic field strength of $2-\mathrm{T}$ is required to compress and heat the preionized hydrogen over a $10^{-3} \mathrm{~s}$ discharge period, with about $60 \%$ of the heated plasma exiting the chamber each period to produce thrust. The unoptimized thruster efficiency is low, peaking at approximately $16 \%$ for an initial hydrogen chamber pressure of 100-Torr. The specific impulse and impulse-bit at this operating condition are 3,500 s and $90 \mathrm{~N}-\mathrm{s}$, respectively, and the required discharge energy is approximately $9 \times 10^{6} \mathrm{~J}$. For a pulse repetition rate of 10 - $\mathrm{Hz}$, the engine would produce an average thrust of $900 \mathrm{~N}$ at 3,500 s specific impulse. Combined with the electrodeless nature of the device, these performance parameters indicate that theta-pinch thrusters could provide unique, long-life propulsion systems for piloted deep space mission applications.

14. SUBJECT TERMS

Advanced propulsion; Plasma physics

\begin{tabular}{|c|c|}
\hline & $\begin{array}{c}\text { 15. NUMBER OF PAGES } \\
17\end{array}$ \\
\hline & $\begin{array}{r}\text { 16. PRICE CODE } \\
\mathrm{AO} 3\end{array}$ \\
\hline $\begin{array}{l}\text { 19. SECUAITY CLASSIFICATION } \\
\text { OF ABSTRACT } \\
\text { Unclassified }\end{array}$ & 20. LIMITATION OF ABSTRACT \\
\hline
\end{tabular}

\begin{tabular}{|c|c|c|}
\hline $\begin{array}{c}\text { 17. SECURITY CLASSIFICATION } \\
\text { OF REPORT } \\
\text { Unclassified }\end{array}$ & $\begin{array}{c}\text { 18. SECURITY CLASSIFICATION } \\
\text { OF THIS PAGE } \\
\text { Unclassified }\end{array}$ & $\begin{array}{c}\text { 19. SECUAITY CLASSIFICATION } \\
\text { OF ABSTRACT } \\
\text { Unclassified }\end{array}$ \\
\hline
\end{tabular}

NSN 7540-01-280-5500

Standard Form 298 (Rev. 2-89) 